\title{
Reflex bradycardia during surgery
}

Reflex bradycardia and sinus arrest may occur in a variety of surgical procedures, from neurosurgery to general abdominal, laparoscopic, opthalmic and facial surgery and even procedures such as liver biopsies and electroconvulsive therapy. In most cases a vagally-mediated reflex has been implicated, although experimental support for this is often lacking. Drugs such as vecuronium, atracurium, halothane, fentanyl and succinylcholine may predispose to this reflex. Premedication with an anticholinergic is usually effective in preventing its occurrence.

Une bradycardie réflexe et/ou un arrêt sinusal peuvent survenir lors de tout un éventail d' interventions allant de la neurochirurgie à la chirurgie abdominale, laparoscopique, ophtalmique et faciale en passant par la biopsie du foie et les électrochocs. Malgré l'absence de confirmation expérimentale solide, on a souvent insisté sur le rôle du nerf vague dans ce réflexe. On sait qu'entre autres, le vécuronium, l'atracurium, l'halothane, le fentanyl et la succinylcholine peuvent en favoriser l'apparition, alors qu'un anticholinergique en prémédication pourra habituellement le prévenir.

Any sudden change in the cardiovascular state of a patient during anaesthesia is potentially dangerous, especially when its cause is obscure. Presented here is a summary of some reported instances of changes in heart rate and blood pressure which have been attributed to a vagal reflex. This phenomenon has been observed during a wide range of procedures, from neurosurgery to general abdominal, laparoscopic, ophthalmic, and facial surgery. In addition, it has also been observed during laryngoscopy, percutaneous liver biopsy, and electroconvulsive therapy (vide infra). Drugs such as vecuronium, atracurium, halothane,

\section{Key words}

COMPLICATIONS: arrest, cardiac, arrhythmia; HEART: arrhythmia, bradycardia, sinus arrest; PARASYMPATHETIC NERVOUS SYSTEM: vaguS; REFLEXES: vagal.

From the Department of Anaesthesia, Toronto General Hospital.

Address for correspondence 10: Dr. D.J. Doyle, Department of Anaesthesia, Toronto General Hospital, 200 Elizabeth Street, Toronto, Ontario, M5G 2 C4. fentanyl, and succinylcholine may facilitate the reflex. Since the reflex is vagally-mediated, premedication with an anti-cholinergic (e.g., atropine or glycopyrrolate) may be a suitable preventative measure.

\section{Reflex bradycardia during abdominal surgery}

A decrease in arterial blood pressure and a change in heart rate may occur with surgical manipulation of abdominal contents. Rocco and Vandam' found that some patients exhibited a fall in blood pressure of about $20 \mathrm{mmHg}$ systolic and $6 \mathrm{mmHg}$ diastolic over a period of 8 to 15 pulse beats immediately after manipulation of the upper abdominal anterior parietal peritoneum. The effect was transient even if the initial stimulus was continued. A similar reflex of greater magnitude and longer duration was noted with displacement of the liver, insertion of the hand into the peritoneal cavity, placement of packing, evisceration, or retraction of the wound edges. Rocco and Vandam explained these findings in terms of tissue deformation, resulting in an increase in vagal tone and a consequent decrease in cardiac contractility and output. A simultaneous bradycardia was present in nearly half the patients.

Smith $^{2}$ attributed some sudden decreases in blood pressure during abdominal surgery to a coeliac plexus reflex. He stated that stimulation of the coeliac plexus (e.g., through handling of upper abdominal viscera) caused a reflex decrease in cardiac output due to increased vagal tone. The accompanying decrease in heart rate was only minor, apparently due to the compensatory effects of the Bainbridge reflex (an increase in heart rate resulting from an increase in the pressure within the large veins or the right atrium). ${ }^{3}$

More recently, Seltzer et al. ${ }^{4}$ observed that traction on the abdominal mesentery resulted in a decrease (20 $\mathrm{mmHg}$ on average) in mean arterial pressure, which was attributed to vasodilatation, manifested as a decrease in systemic vascular resistance, as measured using invasive haemodynamic monitoring. This was often accompanied by an increased heart rate, although instances of bradycardia also occurred.

\section{Bradycardia and hypotension after percutaneous liver biopsy}

Sullivan and Watson ${ }^{5}$ described three patients who developed transient hypotension and bradycardia imme- 
diately after percutaneous liver biopsy. This was attributed to stimulation of the hepatic and coeliac plexuses and the splanchnic and vagal nerves. However, Barrett ${ }^{6}$ suggested that stimulation of the tissue between the liver and the diaphragm might also be responsible.

\section{Bradycardia due to the oculocardiac reflex}

Bradycardia upon traction of the orbit has been documented since the early $1900^{\prime} \mathrm{s}^{7,8}$ and involves a reflex arc; the afferent arm is via parasympathetic fibres in the ciliary nerves and the ophthalmic nerve from the Gasserian ganglion. ${ }^{9}$ These fibres run to the spinal tract of the trigeminal nerve. The adjacent nucleus ambiguus is the origin of the vagus, which forms the efferent arm of the reflex. Many related phenomena have been observed. Robideaux ${ }^{10}$ described a case in which an attempt at disimpaction of a fractured maxilla resulted in abrupt bradycardia which promptly subsided upon cessation of traction. This was attributed to stimulation of terminal branches of the trigeminal nerve through traction on the floor and medial aspect of the orbit. In a similar case, Shearer and Wenstone ${ }^{11}$ reported incidents of bradycardia in two patients undergoing procedures to elevate fractured zygomas. The explanation offered for this observation was the inadvertent stimulation of parasympathetic fibres in the periosteum of the zygoma. In another case, Kerr and Vance ${ }^{12}$ observed a profound bradycardia resulting from an oculocardiac reflex in two patients with previous orbital enucleations. It was speculated that regeneration of the severed axons from the Gasserian ganglion allowed the reflex to occur in spite of an empty orbit. Finally, the observation of Hopkins ${ }^{13}$ that severe bradycardia resulted upon diathermy in the vicinity of the tentorium is explained because the ophthalmic nerve sends branches to the tentorium cerebelli.

Because of the severity of the cardiovascular effects resulting from this relatively common reflex (Mirakhur $e t$ al. ${ }^{14}$ found that 90 per cent of patients in their study exhibited the reflex), the possibility of reflex bradycardia should always be noted when operating near the ophthalmic nerve.

\section{Bradycardia associated with laparoscopy and D\&C} Instances of bradycardia not unlike those reported during abdominal surgery have been recorded during certain gynaecological procedures. Milligan and Beers ${ }^{15}$ encountered a patient undergoing a gynaecological laparotomy who developed 5:1 heart block and eventually asystole immediately after opening the peritoneum. Kirkwood and Duckworth ${ }^{16}$ reported a similar incident in which a patient developed sinus arrest during a dilatation and curettage (D\&C) procedure. In a third case, Clayton ${ }^{17}$ described a patient undergoing laparoscopy and $\mathrm{D} \& \mathrm{C}$ suddenly having bradycardia, progressing to asystole before atropine was administered. A similar case was described by Doyle and Mark. ${ }^{18}$ These events were attributed to parasympathetic stimulation from both peritoneal stretching and cervical dilatation.

Doyle and Mark ${ }^{18}$ noted that when drugs with vagolytic or sympathomimetic effects, such as pancuronium, are used, this reflex is often masked. However, if drugs free of cardiovascular effects, such as vecuronium, are used, the reflex is not masked unless an anticholinergic is also administered. In all four of the above cases, the neuromuscular blocking drug used was vecuronium. However, the peculiarity in Clayton's case ${ }^{17}$ is that even though hyoscine had been given preoperatively, bradycardia was still noted. This is in contradistinction with the studies of Caldwell et al. ${ }^{19}$ in which 52 patients undergoing laparoscopic sterilization were given IV vecuronium and IM hyoscine and developed tachycardia during the operation.

\section{Bradycardia during laryngoscopy}

Podolakin and Wells ${ }^{24}$ described three patients, each with a history of cardiac disease, who developed severe bradycardia at the beginning of surgery just after laryngoscopy and spraying of the cords with lidocaine. This response was believed to have been caused by reflex vagal activity from stimulation of the larynx with insufficient fentanyl anaesthesia. After increasing the induction dose of fentanyl, Podolakin and Wells did not encounter any further cases of this reflex. The exact pathway of this reflex is not known but the fibres of the superior laryngeal nerve have been ruled out by the work of Jacobs et al. ${ }^{25}$ using nerve stimulation experiments in a rat model.

\section{Bradycardia associated with electroconvulsive therapy}

There have been many reports of bradycardia during electroconvulsive therapy (ECT). Marks ${ }^{26}$ noticed that parasympathetic discharge occurred immediately after the current is applied and resulted in severe bradycardia and hypotension. This was supported by Anton et al. ${ }^{27}$ who studied the effects of ECT in dogs. Although atropine has been used routinely prior to the procedure, its use is now being questioned since some (Wyant ${ }^{28}$ ) have found it to contribute nothing to patient safety and may be harmful because of cardiac sphincter relaxation during convulsive movements which increases the likelihood of regurgitation.

\section{Psychogenic cardiac arrest}

Frerichs et al. ${ }^{29}$ reported an unsedated patient who underwent arthroscopic examination of a knee with epidural anaesthesia. Upon being told of his poor prognosis, the patient suddenly developed a bradycardia leading to asystole. The explanation offered was that sympathetic blockade by the epidural anaesthetic, coupled with 
increased vagal tone in response to stress occurred in a passive-coping environment (i.e., a situation in which the subject had no opportunity to modify his position).

\section{Effects of drugs}

Whatever the causes of these cardiovascular changes certain drugs are associated with the reflex. The newer, non-depolarizing neuromuscular blocking drugs vecuronium and atracurium are good examples. Pollok ${ }^{30}$ described a patient who had been given vecuronium who developed bradycardia that led to asystole. May, ${ }^{31}$ and Higgins and Thorp ${ }^{32}$ encountered similar cases. Hardy ${ }^{33}$ observed bradycardia in a patient who had been administered atracurium. In all four cases, atropine caused the pulse to recover. Atracurium, and especially vecuronium, are known for their cardiovascular stability, their main site of action being on the nicotinic receptors, with little muscarinic activity. Older muscle relaxants such as pancuronium have vagolytic effects, helping to mask vagally mediated cardiovascular effects. Thus, agents lacking vagal effects may allow drug- or reflex-induced bradycardia to occur more easily. Pryne and Edwards ${ }^{34}$ suggested that the increased use of vecuronium, instead of pancuronium, may increase the occurrence of the oculocardiac reflex. Cozanitis et al. ${ }^{35}$ recently confirmed vecuronium's non-vagolytic property and recommended that an anticholinergic such as atropine or glycopyrrolate also be used with vecuronium. Mirakhur et al. ${ }^{14}$ compared the efficacy of atropine and glycopyrrolate in preventing the oculocardiac reflex and found both drugs to be equally effective when given intravenously. However, glycopyrrolate proved to be slightly superior, since it induced tachycardia of a smaller magnitude than atropine, which is particularly important in older patients where tachycardia can be as harmful as bradycardia. Coventry et al. ${ }^{36}$ came to similar conclusions in a comparable study comparing the two drugs.

Vecuronium has also been associated with cardiac arrhythmias other than sinus bradycardia and sinus arrest. Yeaton and Teba ${ }^{37}$ reported an incident in which a patient undergoing noninvasive radiographic studies was given vecuronium on two occasions. Each time, an episode of sinus node exit block developed about five minutes after its administration which resolved spontaneously within a few minutes. Other cases were described by Milligan and Beers, ${ }^{15}$ and Kirkwood and Duckworth. ${ }^{16}$

Halothane causes bradycardia by interfering with calcium channels, resulting in a reduction in contractility and a slowing of conduction (Maze and Mason). ${ }^{38}$ Amdt et al. ${ }^{39}$ have also shown that fentanyl causes bradycardia, possibly mediated through opiate receptors. A comprehensive summary of the effects of fentanyl and a description of the bradycardia induced by morphine have been presented by Bovill et al..$^{40}$ Therefore, when using any of these drugs in large doses, it is advisable also to consider administering an anticholinergic.

There have also been reports implicating succinylcholine with bradycardia. McLeskey et al. ${ }^{41}$ described two patients who developed bradycardia leading to asystole within a minute of succinylcholine administration to aid intubation. In both cases, nodal rhythm resumed spontaneously after 20-30 seconds. Stimulation of cardiac cholinergic receptors or carotid baroreceptors by the succinylcholine was given as a possible explanation.

\section{Discussion}

A variety of surgical stimuli may result in reflex bradycardia. In the case of the oculocardiac reflex the pathways have been well-established by clinical studies and neuroanatomical investigations. However, in almost all other examples, including variants of the oculocardiac reflex, detailed evidence for the pathways involved are generally lacking, so that reflex mechanisms remain speculative. This does not detract from our ability to anticipate, detect, and treat reflex bradycardia.

It is not always clear what degree of bradycardia is tolerable. Certainly, if is associated with hypotension or electrocardiographic changes suggestive of ischaemia immediate action (e.g. , atropine $0.6 \mathrm{mg} \mathrm{IV}$ ) is warranted. In general, a heart rate of less than 40 beats per minute, even without complications, also warrants treatment. In some cases sinus bradycardia may progress to sinus arrest very rapidly. External cardiac compressions may be needed to circulate any drugs administered if this should occur.

In paediatric anaesthesia, where patients exhibit a greater degree of vagal tone, atropine is often given preoperatively to reduce the likelihood of reflex bradycardia. In adults it may also be advisable to use an anticholinergic agent concomitantly when reflex bradycardia is anticipated.

\section{References}

1 Rocco $A G$, Vandam $L D$. Changes in circulation consequent to manipulation during abdominal surgery. JAMA 1957; 164: 14-8.

2 Smith $B H$. The nature and treatment of the coeliac-plexus reflex in man. Lancet $1953 ; 2: 223-7$.

3 Schmidt JE. Attorney's dictionary of medicine and word finder. New York: Matthew Bender and Company Inc., 1988: B-12

4 Seltzer JL, Ritter DE, Starsnic MA, Marr AT. The hemodynamic response to traction on the abdominal mesentery. Anesthesiology 1985; 63: 96-9.

5 Sullivan $S$, Watson WC. Acute transient hypotension as a complication of percutaneous liver biopsy. Lancet 1974; 1: 389-90. 
6 Barrett GM. Hypotension after percutaneous liver biopsy. Lancet 1974; 1: 624.

7 Aschner $B$. Ueber einen bisher noch nicht beschricbenen reflex vom auge auf kreislauf und atmurg. Verschwinden des radialispulses bei druck auf das auge. Wien-klin Wchnschr 1908; 21: 1529. Cited in: Moonie GT, Rees DL, Elton D. The oculocardiac reflex during strabismus surgery. Can Anaes Soc J 1964; 11: 621-32.

8 Dagnini $G$. Intorno ad un riflesso provocato in alcuni emplegici collo stimulo della cornea e colla pressione sul bulbo oculare. Bull Sci Med 1908; 8: 380. Cited in: Moonie GT, Rees DL, Elton D. The oculocardiac reflex during strabismus surgery. Can Anaes Soc J 1964; 11 : 621-32.

9 Moonie GT, Rees $D L$, Elton $D$. The oculocardiac reflex during strabismus surgery. Can Anaes Soc J 1964; 11: 621-32.

10 Robideaux $V$. Oculocardiac reflex caused by midface disimpaction. Anesthesiology 1978; 49: 433.

11 Shearer ES, Wenstone R. Bradycardia during elevation of zygomatic fractures. A variation of the oculocardiac reflex. Anaesthesia 1987; 42: 1207-8.

12 Kerr WJ, Vance JP. Oculocardiac reflex from the empty orbit. Anaesthesia 1983; 38: 883-5.

13 Hopkins CS. Bradycardia during neurosurgery - a new reflex? Anaesthesia 1988; 43: 157-8.

14 Mirakhur RK, Jones CJ, Dundee JW, Archer DB. IM or IV atropine or glycopyrrolate for the prevention of oculocardiac reflex in children undergoing squint surgery. Br J Anaesth 1982; 54: 1059-63.

15 Milligan $K R$, Beers $H T$. Vecuronium-associated cardiac arrest. Anacsthesia 1985; 40: 385.

16 Kirkwood I, Duckworth RA. An unusual case of sinus arrest. Br J Anaesth 1983; 55: 1273.

17 Clayton $D$. Asystole associated with vecuronium. $\mathrm{Br} \mathrm{J}$ Anacsth 1986; 58: 937.

18 Doyle DJ, Mark PWS. Laparoscopy and vagal arrest. Anaesthesia 1989; 44: 448.

19 Caldwell JE, Braidwood JM. Simpson DS. Vecuronium bromide in anaesthesia for laparoscopic sterilization. $\mathrm{Br}$ J Anaesth 1985; 57: 765-9.

20 Keith $L$, Silver A, Becker $M$. Anesthesia for laparoscopy. J Reprod Med 1974; 12: 227-33.

21 Motew M, Ivankovich AD, Bieniarz J, Albrecht RF, Zahed $B E$, Scommegna $A$. Cardiovascular effects and acidbase and blood gas changes during laparoscopy. Am J Obstet Gynecol 1973; 115: 1002-12.

22 Hodgson C, MCClelland RMA, Newton JR. Some effects of the peritoneal insufflation of carbon dioxide at laparoscopy. Anaesthesia 1970; 25: 382-90.

23 Scott $D B$, Julian $D G$. Observations on cardiac arrythmias during laparoscopy. Br Med J 1972; I: 411-3.
24 Podolakin W, Wells $D G$. Precipitous bradycardia induced by laryngoscopy in cardiac surgical patients. Can J Anaesth 1987; 34: 618-21.

25 Jacobs JR, Wetzel AB, Hast $M H$. Laryngeal aortic baroreceptor pathways and cardiac arrhythmia. Arch Otolaryngol 1976; 102: 77-9.

26 Marks $R J$. Electroconvulsive therapy: physiological and anaesthetic considerations. Can Anaesth Soc J 1984; 31: $541-8$.

27 Anton $A H$, Uy DS, Redderson CL. Autonomic blockade and the cardiovascular and catecholamine response to electroshock. Anesth Analg 1977; 56: 46-54.

28 Wyant GM. Electroconvulsive therapy. Can Anaesth Soc J 1981; 5: 491.

29 Frerichs RL, Campbell J, Bassell GM. Psychogenic cardiac arrest during extensive sympathetic blockade. Anesthesiology 1988; 68: 943-4.

30 Pollok AJP. Cardiac arrest immediately after vecuronium. Br J Anaesth 1986; 58: 936-7.

31 May JR. Vecuronium and bradycardia. Anaesthesia 1985; 40: 710 .

32 Higgins $M$, Thorp JM. Non-vagolytic anaesthetic sequence - sinus arrest. Anaesthesia 1986; $41: 89$.

33 Hardy PAJ. Atracurium and bradycardia. Anaesthesia 1985; 40: 504-5.

34 Pryne SJ, Edwards JC. Vecuronium and the oculocardiac reflex. Anaesthesia 1985; 40: 88-9.

35 Cozanitis DA, Pouttu J, Rosenberg PH. Bradycardia associated with the use of vecuronium. A comparative study with pancuronium with and without glycopyrronium. Anaesthesia 1987; 42: 192-4.

36 Coventry DM, McMenemin I, Lawrie S. Bradycardia during intra-abdominal surgery. Modification by preoperative anticholinergic agents. Anaesthesia 1987; 42 835-9.

37 Yeaton $P, T e b a L$. Sinus node exit block following administration of vecuronium. Anaesthesiology 1988; 68: 177-8.

38 Maze A, Mason DM. Actiology and treatment and halothane induced arrhythmias. Clinics in Anaesthesiology 1983; 1: 301-21.

39 Arndt JO, Mikat M, Parasher C. Fentanyl's analgesic, respiratory, and cardiovascular actions in relation to dose and plasma concentration in unanesthetized dogs. Anesthesiology 1984; 61: 355-61.

40 Bovill JG, Sebel PS, Stanley TH. Opioid analgesics in anesthesia: with special reference to their use in cardiovascular anesthesia. Anesthesiology 1984; 61: 731-43.

41 McLeskey CH, McLeod DS, Hough TL, Stallworth $J M$. Prolonged asystole after succinylcholine administration. Anesthesiology 1978; 49: 208-10. 